\title{
Building Performance Simulation in Brazil: A systematic review
}

\author{
Adriano Felipe Oliveira Lopes ${ }^{1}$, Caio Frederico e Silva ${ }^{1}$ \\ ${ }^{1}$ University of Brasilia, Brasilia, Brazil
}

\begin{abstract}
This paper presents a systematic review of Building Performance Simulation (BPS) in Brazil. BPS became more recurrent in the country after the publication of the Building Labelling Program, between 2009 and 2010, and the National Standard Regulation (NBR) 15575, in 2013. From this perspective, this research drafts a framework as a result of a systematic review of literature in which 56 papers were selected from three international databases: the Brazilian collection Scielo, and other two known databases - Web of Science and Science Direct. The review recognized three main topics: Sensistivity Analysis, Thermal Performance and Daylighting. In this context it was noticed some subjects poorly explored as user behavior, modeling interoperability and the relation between regulations, towards new research fields.
\end{abstract}

\section{Introduction}

The 1970s witnessed an international energy crisis. In due of that, the first politics related to energy efficiency have been elaborated, based on methods to assess the performance of buildings and sizing of mechanical systems (Mendes et al., 2005; Freire et al., 2008; Schimid, 2008; Lamberts et al., 2014). This context pushed towards the development of the first building simulation software still limited to load calculations and energy analysis (Clarke, 2001; Spitler, 2006; Hernandez, 2015). Over the time, these tools have evolved from analytical formulations to dynamic approaches representing each possible energy flow path and its interactions from an abstract model (Clarke, 2001; Augenbroe, 2004; Spitler, 2006).

Trying to emulate the reality, Building Performance Simulation (BPS) deals with generic models to denote complex entities (Clarke, 2001; Carlo, 2008). Such models reduce in a limited subset of elements, specific qualities of a characterized entity allowing the prediction of its behavior under dynamic conditions (Mahdavi, 2003); Augenbroe, 2004). Carlo \& Lamberts (2010) states that a model represents a numerical description of the characteristics involved in the thermal and energetic performance of a building, sufficient to understand its inherent thermodynamic phenomena.

In the 1980s in Brazil the first research involving BPS simulation were developed (Mendes et al., 2001).
However, only at the end of the 1990s, due to the low water level of Brazilian hydro plants, building energy have been brought to the agenda towards to the development of local standards (Lamberts et al., 2014). In the early 2000s the Decree n.4059 was published which has stated the Energy Efficiency Indicators Management Committee, responsible for the elaboration of technical requirements, for new projects, with reference indicators of buildings energy consumption. This scenario incited the recurrent use of building simulation in an increasing number of Brazilian research. During the $7^{\text {th }}$ IBPSA Conference, all Brazilian authors were consulted to establish a scenario regarding the use and development of building simulation in Brazil (Mendes et al., 2001). At the time, the absence of energy efficiency standards was marked up as the main limitation to the exercise of building simulation by a larger number of researchers. Furthermore, the quality of available weather data, an appropriate representation of naturally ventilated buildings and interoperability between tools was shown as challenges towards the increase of buildings simulation use in Brazil.

In February 2009, the first version of the Technical Regulation for the Energy Efficiency of Commercial Buildings (RTQ-C) was published, in the framework of the Brazilian Labelling Program (PBE-Edifica) (INMETRO, 2009). The related document presents two procedures to classify buildings energy efficiency: the first one is prescriptive and based on algebraic operations, the second one, uses results from virtual models developed in a software validated by the ASHRAE Standard 140 (ASHRAE, 2007).

The RTQ-C approaches the building simulation through the relationship between a baseline and representative models of a proposed project, which has to be developed with its original features, to represent the real building. Besides, the baseline model is used as a source of comparison based on the proposed building and characterized under defined parameters depending on the desired level of energy efficiency. The method adopted by the RTQ-C is based on the Energy Budget Costs method presented by ASHRAE's Standard 90.1 (ANSI/ASHRAE/IESNA, 2009).

From June 2014, with the promulgation of the Federal Normative Instruction - MPOG/SLTI No 02 - the energy 
efficiency classification of public buildings became mandatory, emphasizing the relevance of the RTQ-C and its methods. According to the Energy Efficiency National Plan, published in 2011, until 2025 the obligation should extend to all typologies of commercial buildings, services, and public, and is expected to 2030, to every kind of residential buildings.

In July 2013 the current version of the Brazilian Standard NBR 15575 (ABNT, 2013) was published. This document establishes requirements for the whole building performance during its useful lifetime. The NBR 15575 Standard presents the simulation among the methods to evaluate the building's thermal performance. It represents a milestone in the national context of BPS practice, since the compliance of all current technical standards is compulsory, according to the Article 39 of the Consumer Protection Code (Law 8.078/90) (Sorgato et al., 2014; Santo et al., 2014). Because of the context concerning the energy efficiency labeling, but mainly to the required conformity with the standards, the use of simulation tools tends to become even more recurrent and the methods it involves even more developed.

Considering the background, this paper intends to expose a Brazilian scenario regarding the use of building simulation, following up the research instigated by Mendes et al. (2001). The purpose is to facilitate a panoramic view of professional and research groups towards the development of original studies. In this sense, the pursued path consisted of the development of a Systematic Literature Review (SLR).

The adjective "systematic" according to Neves et al. (2018) is related to the dependence of the method designed to guarantee its impartiality, precision, audibility, replicability, and updating. In this sense, Gough et al. (2012) say that this approach means to identify a representative sample of studies avoiding bias (i.e. propensity to present a partial perspective over also valid others) from study selection. The definition of this sample adopts a theoretical approach, which should be defined more clearly before the review, to establish the research hypothesis and interpret its results.

Dresche, Lacerda and Antunes Jr. (2015) states that SLR aims to conduct over a theoretical and practical framework related to the instruments used to solve a particular or a class of problems. SLR consists of the mapping of primary studies on a specific research topic followed by its critical evaluation and aggregation of results to identify gaps to observe in a subject synthesis. This method is, therefore, an essential instrument for the definition and conduction of a defined research problem.

SLR involves a large amount of information to be managed, and then it is fundamental to invest in the preparation of a proper strategy to deal with primary studies. From this perspective, the consolidation and aggregation of the results represent, much more than a collection of different researched elements. The strategy is based on the formulation of the problem to be solved and a framework that indicates what to look for, where to look, how to minimize bias and which studies to consider, as a structure to the accomplishment of the research.

Gough et al. (2012) established a framework to design systematic reviews responsible for the definition of its scope and approach, components and depth of investigation, as well as its analytical profile at the end of the research. The author described two types of research, "aggregative" and "configurative," that are, respectively associated to the accomplishment of experiments, or development of a rendered scenario of theories from the understanding of patterns in a sufficient number of studies. It seeks to clarify and arrange information, towards its enlightenment through new forms of perception.

\section{Methods}

The SLR approach adopted was based on the methods proposed by Gough, Thomas \& Oliver (2012) and Dresch, Lacerda \& Antunes (2015). The longitudinal nature of a SLR provides the ability to evidence state of the art through the inspection of general principles at a higher level of conceptual abstraction. In this sense, the characterization of the studies in a SLR must be done in a pragmatic, precise way (Gough et al., 2012) and proper coherent to map and contribute with a critical reading of a specific theme in order to identify demands to be met regarded to it (Neves et al., 2018).

The presented SLR comprises three different stages: planning, conduction and consolidation - as shown in Error! Reference source not found. The Planning step c onsistes by the definition of a systematic mapping based on the selection of databases, formulation of the research strings and its protocol. In the Conduction stage, several studies that met the research scope were identified and their theoretical and methodological approaches, considering only the production of Brazilian researchers. The Consolidation stage embodies a process of synthesis, in which the arrangement of surveyed studies is inferred, and it's sought to recognize patterns among them.

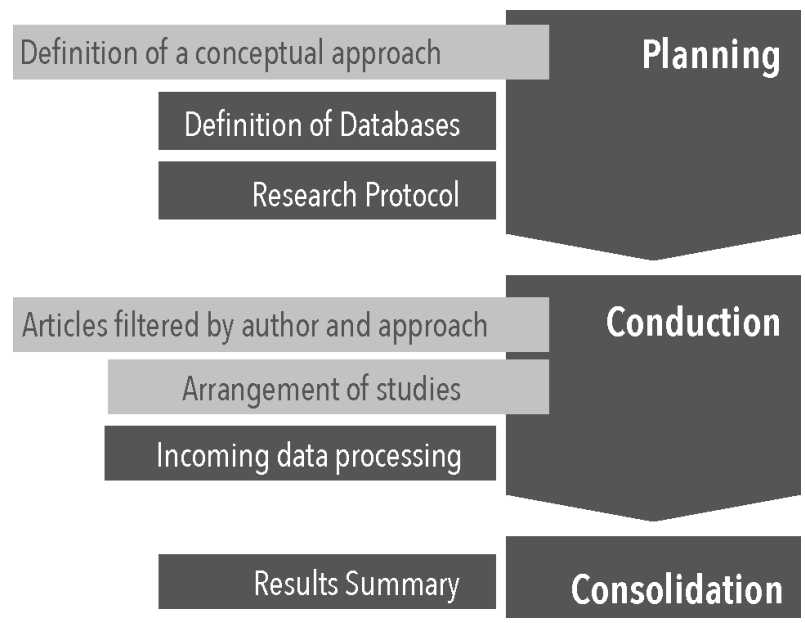

Figure 1: Flowchart applied to this research. Adapted from Neves et al (2012).

The databases used in this investigation, due to its relevance according to a preliminary research in "Periódico Capes" platform, were Science Direct, Web of 
Science and Scielo. The last one indexes the catalog of "Ambiente Construído", the main journal in the field of Built Environment Technology in Brazil. Subsequently the selection of the databases, the research strings were defined. In those platforms, to avoid abridged and generic results, the term BUILDING SIMULATION among relatives has been adopted connected by the Boolean intersection operator $A N D$ to the terms BRAZIL and THERMAL COMFORT. Concerning both databases, it was accepted, for the research strings to be part of the title, keywords and abstract of the papers, that should be published in a period of ten years, from 2008 to 2018 .

Although there is no unique way to structure a research strategy, Morandi and Camargo (2015) suggested a protocol, aimed at SLR with academic purposes. Its application, as an integrated process to a systematic review, results in several publications restricted to a specific scope. Thus, papers not elaborated by Brazilian researchers, that did not portray Brazilian cases or did not use simulation in their methods were excluded. The following image presents the application of the protocol proposed by Morandi and Camargo (2015) to address a SLR towards the development of the scene of BPS in Brazil.

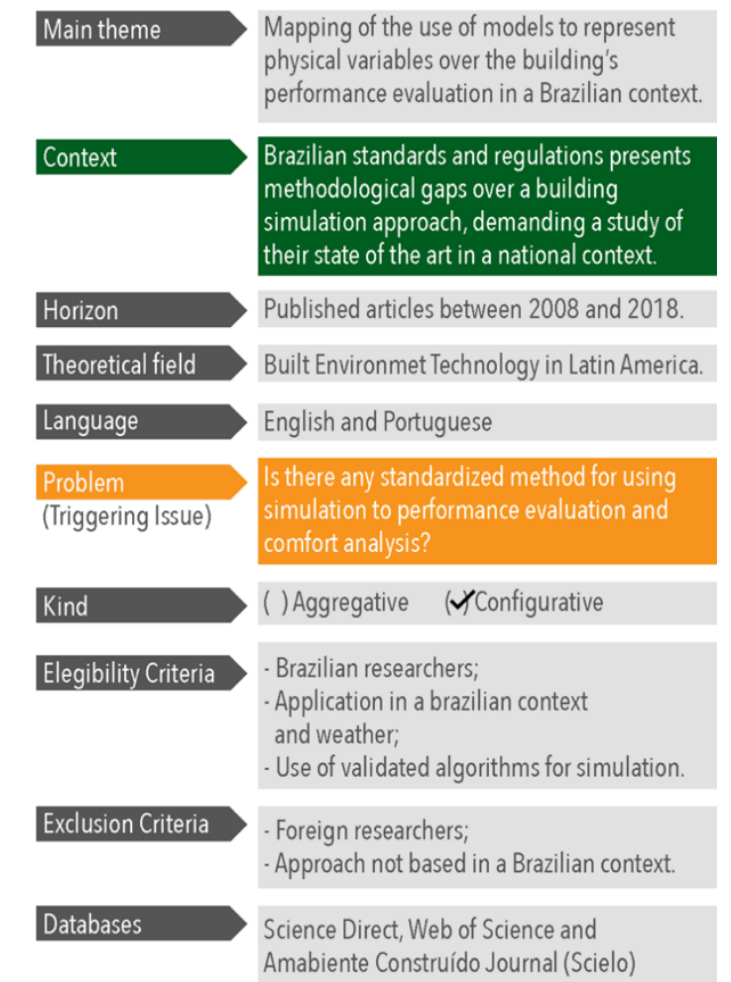

Figure 2: RSL protocol applied to the presented research suggested by Morandi and Camargo (2015).

The software Mendeley was used as a bibliographic management tool, which enabled the organization of the surveyed studies. It allowed an objective reading of the bibliographic data as a path over the selection of the studies which attended to the scope of the review.

Once the volume of publications was defined, it was possible to quantify, deepen and synthesize in the Conduction stage. In this stage, a spreadsheet for the organization of the selected papers was developed. They were then registered by author, associated institution and its category (federal or state, private and company) and by, title, keywords, year of publication, its main theme and provenance database.

The identification of the main theme of the selected papers has been based on a keywords co-occurrence analysis. This purpose was pursued using the software VOS Viewer, an interface for visualization and analysis of bibliometric and sociometric data, which used the data bank raised and managed at Mendeley. To each selected paper, a summary of the content, purpose, and conclusion has also been assigned, as a result of a more accurate read, leading over a proper subject relation between the studies.

\section{Results}

Besides the number of studies involving building performance simulation, the results shows the main addressed topics and others not properly explored. Out of a total of 192 papers identified in the set of considered databases, only 56 were selected attending to the scope of the research. These studies have been published by 82 researchers from 26 institutions among public universities and private schools as well as private offices. The following picture presents the number of identified papers and selected ones by database.

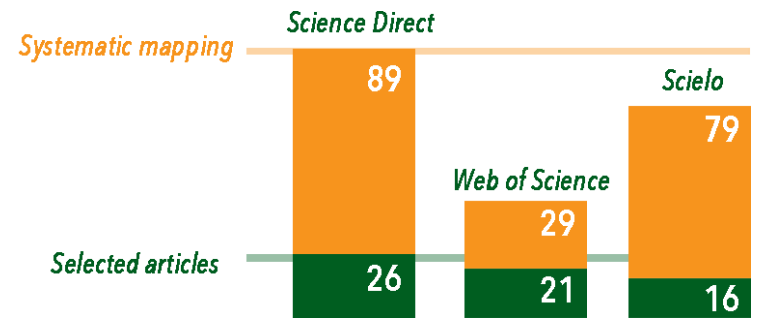

Figure 3: Relation between the set of identified papers.

By relating the keywords co-occurrence using VOS Viewer, it was possible to map the main addressed topics in the 56 selected papers. The most relevant keywords identified were "BUILDING SIMULATION", "COMPUTER SIMULATION" and "ENERGY EFFICIENCY", pointing out brad issue to the whole research set, which covers the entire set of the studies.

This information indicates that the use of BPS tools in the whole bunch of selected papers has a focus on the energy efficiency of the buildings over its environmental and composition quality. Furthermore, there is some disagreement regarding the employed vocabulary, since the expressions "building performance simulation" and "building energy simulation" appears between the less occurring terms.

The co-occurrence analysis also indicated the arrangement of three thematic groups set up by keywords occurring at least three times in the total of selected papers. The first group focuses on "SENSITIVITY ANALYSIS". It covers all the topics related to the sensitivity of input data over the simulation results and relates to the terms "thermal comfort", "uncertainty analysis", "user behavior", "energy consumption" and 
"natural ventilation". The main references that composes this group are reported in the the Table 1.

Table 1: References for Sensitivity Analysis and engaged BPS tool.

\begin{tabular}{|c|c|}
\hline $\begin{array}{c}\text { References about Sensitivity } \\
\text { Analysis }\end{array}$ & Software Engaged \\
\hline Batista et al. (2011) & EnergyPlus \\
\hline Silva; Ghisi (2014a) & EnergyPlus \\
\hline Silva; Ghisi (2014b) & EnergyPlus \\
\hline Silva et al. (2014a) & EnergyPlus \\
\hline Rackes et al. (2016) & EnergyPlus \\
\hline Bre et al. (2016) & EnergyPlys \\
\hline Silva; Ghisi; et al. (2016) & EnergyPlys \\
\hline Silva; Almeida; et al. (2016) & EnergyPlus \\
\hline Silva; Ghisi; et al. (2016) & EnergyPlys \\
\hline Bavaresco; Ghisi (2018) & EnergyPlus \\
\hline
\end{tabular}

The second group, "THERMAL PERFORMANCE", refers to a set of keywords related to studies whose purpose was to present thermal performance assessments based on consolidated methods or to suggest a methodological review. The last group is centered in the keyword "DAYLIGHTING", which points to a shallow approach regarding the relationship between performance evaluation typologies. Them main references related to these groups are reported in Table 2 and Table 3.

Table 2: References for Thermal Performance and engaged BPS tool.

\begin{tabular}{|c|c|}
\hline References about Thermal Comfort & \\
\hline Egan; Finn; Deogene Soares; et al. (2018) & DesignBuilder \\
\hline Melo, A.P. et al. (2014) & EnergyPlus \\
\hline H. Borgstein; Lamberts (2014) & DesignBuilder \\
\hline Neto; Fiorelli (2008) & EnergyPlus \\
\hline Triana et al. (2018) & - \\
\hline Balvedi et al. (2018) & EnergyPlus \\
\hline Silva; Almeida; et al. (2016) & EnergyPlus \\
\hline Melo et al. (2016) & EnergyPlus/ESP-r \\
\hline Borgstein et al. (2016) & EnergyPlus \\
\hline Berger et al. (2016) & Domus/HM-PGD \\
\hline Sorgato et al. (2016) & EnergyPlus \\
\hline Neto; Fiorelli (2008) & EnergyPlus \\
\hline De Oliveira Neves; Marques (2017) & EnergyPlus \\
\hline Papa et al. (2007) & EnergyPlus \\
\hline Invidiata; Ghisi (2016) & EnergyPlus \\
\hline Dávi et al. (2016) & EnergyPlus \\
\hline Melo, A.P. et al. (2014) & EasyNN-Plus \\
\hline Da Silva Júnior et al. (2013) & EnergyPlus \\
\hline Gomes et al. (2013) & EnergyPlus \\
\hline Pereira; Ghisi (2011) & EnergyPlus \\
\hline Leao et al. (2009) & EnergyPlus \\
\hline Ferreira et al. (2017) & EnergyPlys \\
\hline Sorgato et al. (2016) & EnergyPlus \\
\hline Didoné et al. (2014) & EnergyPlus \\
\hline Rupp; Ghisi (2013a) & EnergyPlus \\
\hline Nakamura et al. (2013) & EnergyPlus \\
\hline Barbosa et al. (2013) & EnergyPlus \\
\hline Roriz et al. (2012) & EnergyPlus \\
\hline Souza et al. (2011) & EnergyPlus \\
\hline Sorgato et al. (2014b) & EnergyPlus \\
\hline
\end{tabular}

Table 3: References for Daylighting and engaged BPS tool.

\begin{tabular}{|c|c|}
\hline References about Daylighting & \\
\hline Didoné; Pereira (2010) & EnergyPlus \\
\hline Ramos; Ghisi (2010) & EnergyPlus \\
\hline Greici; Ghisi (2010a) & EnergyPlus/Daysim \\
\hline Lima; Caram (2015) & EnergyPlus \\
\hline Schaefer; Ghisi (2016) & EnergyPlus/Daysim \\
\hline Rupp; Ghisi (2017) & EnergyPlus/Daysim \\
\hline Costa et al. (2017) & EnergyPlus \\
\hline Fernandes et al. (2018) & EnergyPlus/Daysim \\
\hline
\end{tabular}

The Figure 4 represents the keywords co-occurrence analysis generated from VOS Viewer and organizes it in a diagram for clarity in the relation between the raised topics. It indicates, as well, the proportion of papers by its relative main theme and the number of papers distributed among the thematic groups identified and main reference author.

Building Simulation, Computer Simulation, Energy Efficiency

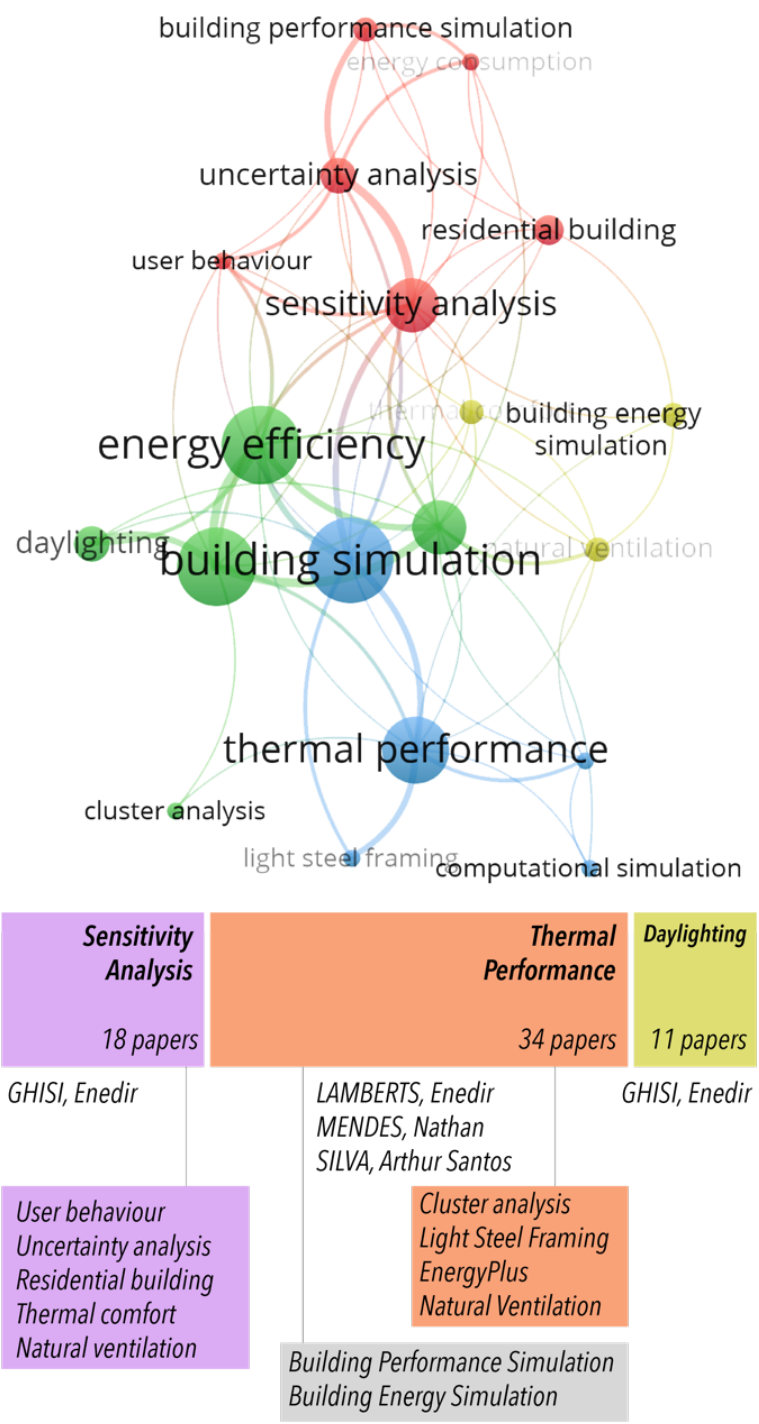

Figure 4: Keywords co-occurrence analysis filtered by raised topic and group of papers by main theme, proportion and main reference authors. 
In addition to the keywords co-occurrence analysis, the software VOS-Viewer also served to recognize the most relevant authors in the review, considering a minimum of 4 citations per document. The following figure points to the significance of the works of Enedir Ghisi (UFSC), Roberto Lamberts (UFSC), Nathan Mendes (PUC-PR) and Arthur Silva e Santos (UFSC).

\section{lamberts, roberto}

mendes, nathan

\section{ghisi, enedir \\ silva, arthur santos}

Figure 5: Most relevant authors in the selected papers.

\section{Discussion}

Referring to an instrumental approach of BPS in Brazil, speculation around the model setting up is recurrent. This question has addressed researchers towards the exploration of methodological patterns and analyse the more sensitive variables to the output results (Egan et al., 2018; Papa et al., 2007; Silva \& Ghisi, 2014, Sorgato et al., 2014; Pereira \& Ghisi, 2011) as well as input data abridgment (Silva \& Ghisi; 2014; COSTA et al., 2017) . In this perspective, the demand for modeling simplification is critical over the input's data degree of clarity and precision. This statement supports an upward relevance of studies related to Sensitivity Analysis, specially in a critical positioning to the methodological approach currently presented by standards and regulations.

Another recurrent issue regarding the relevance of the topic in the selected papers, is the user's influence in the building's performance (Silva \& Ghisi, 2014a; Bavaresco \& Ghisi, 2018), often intricate by a large number of variables involved, associated to several odds of occupation patterns. Example of these variables are vents and blinds operation, which impacts directly the air conditioning energy consumption (Freire et al., 2011; Bavaresco and Ghisi, 2018) and the rapport between user occupation and cooling systems (Rupp \& Ghisi, 2013).

The review has plotted two distinct natures of research based on case studies: the ones focused on a specific demand to discuss its particular results and those interested in trends to investigate phenomena through a specific instance as a part of a sample.

The first nature regards to the analysis of buildings' performance, comforts measurement and consumption profiles, due to the adoption of appropriate strategies related to shading, ventilation, natural lighting, and envelope towards more efficient scenarios. The second one refers to studies aiming to develop a comprehensive approach or parametric process over the understanding of a thermodynamic phenomenon and how it behaves in the adopted simulation tool.

Concerning to the methodological analysis approach, some studies have pointed an expressive lack of clarity in its procedures, as well as some limitations in its evaluation criteria. Sorgato et al. (2014), in respect to the simulation method proposed by the current NBR 15575 , observed inaccuracies in the output data under the influence of soil. Related to the same method, Silva et al. (2014), investigated uncertainties regarding the definition of the typical summer and winter days, also responsible for results inaccuracies. The comparison of the methods presented by the Brazilian Performance Standard and the Technical Regulation for the Level of Energy Efficiency of Commercial Buildings (RTQ-C) provided by Silva and Ghisi (2014) presented some discrepancies between them due to the lack of objectivity in both procedures.

In the same framework, Melo, Sorgato e Lamberts (2014) noticed, for a specific range of energy efficiency, equivalence between the methods proposed by the ASHRAE Standard 90.1 and Brazilian Technical Regulations for the Level of Energy Efficiency of Commercial Buildings (RTQ-C) and Residential Buildings (RTQ-R). Following, Silva, Ghisi and Lamberts (2016) compared the comfort indicators proposed by ASHRAE Standard 55 for office buildings indicating similar trends despite the different results. In this sense, Borgstein, Lamberts and Hensen (2016) related the need to improve the rapport between the currently available methods to develop its clarity and simplification.

An approach presented as scarce by the papers focusing on Daylighting is the use of integrated simulations that consider besides thermodynamic and energetic aspects those related to lighting, acoustics, $\mathrm{CO} 2$ emissions, etc. Among the selected papers, only two of them studied the interoperability between the EnergyPlus and Radiance algorithms. Didoné e Pereira (2010) sought to circumvent limitations regarding the use of EnergyPlus to predict consumption in coherence with daylight environmental quality integrating it with Daysim to calculate a proper Daylight Coefficient index. Greici and Ghisi (2010), on the other hand, evaluated the quality of input data regarding daylight in EnergyPlus by the comparison of its Daylight Factor (FLD) index with Daysim and Troplux. These authors concluded then that this algorithm does not perform raytracing calculation adequately and presents a substantial incoherence related to diffuse lighting.

\section{Conclusion}

The SLR method proved to be suitable for the construction of a panoramic scenario regard the solution of a specific problem, in this case, the state of art of BPS in Brazil. Nevertheless, while a SLR should cover all relevant primary studies, the exhaustive search is, in most cases, much more of an intent than a reality as it is almost impossible to ensure the mapping of all the relevant studies. It is important to emphasize that the presented review is limited to the scale of the building. 
The keywords co-occurrence analysis showed the inherence of the subject Energy Efficiency in the whole set of the selected papers. Although, thermal comfort and indoor air quality were treated as important towards the performance of the whole building. The review also pointed to a potential need of more pragmatism in the use of building simulation tools due to the lack of a unanimous approach in Brazilian standards that orients the practice, outputs understanding and uncertainty data.

Some subjects have been poorly explored or superficially addressed, for instance: user behavior, interoperability of simulation algorithms and methodological relation between regulations involving building simulation. Besides, there is plenty of limitation around the interoperability of models and uncertainty regarding the proper insertion of input data. In this direction, the review noticed as well as considerable adversity concerning the definition of the best simulation tool and most relevant parameters for the proper interpretation of the output data. The availability of such overview of BPS in Brazil contributes to the formation of new researchers in the field and the development of new research. Therefore, this work requires periodic reviews and update in consonance with the evolution of the number of publication in the field. Besides, the approach to other databases and search terms composition may be pertinent to future works.

\section{References}

American National Standards Institute; American Society of Heating, Refrigerating and Air Conditioning Engineers (2007). Standard method of test for the evaluation of building energy analysis computer programs (ANSI/ASHRAE 140-2007).

American National Standards Institute; American Society of Heating, Refrigerating and Air Conditioning Engineers (2009). Energy Standard for buildings except low-rise residential buildings (ANSI/ASHRAE/IESNA 90.1-2007).

ABNT - Brazilian Association of Standards (2013). Edificações Habitacionais - Desempenho Parte 1: Requisitos gerais Prefácio. (NBR 15575-1).

Augenbore, G. L. M. (2004). Trends in building simulation. In: MALKAWI A.; AUGENBROE G. Advanced building simulation. Spon Press. New York (USA).

Bavaresco, M. V.; Ghisi, E. (2018). Influence of user interaction with internal blinds on the energy efficiency of office buildings. Energy \& Buildings (166), 538-549.

Carlo, J. C (2008). Desenvolvimento de Metodologia de Avaliação da Eficiência Energética do Envoltório de Edificações Não-residenciais. PhD Thesis. Universidade Federal de Santa Catarina. Santa Catarina (Brazil).

Carlo, J. C.; Lamberts, R. (2010). Parâmetros e métodos adotados no regulamento de etiquetagem da eficiência energética de edifícios: parte 2: método de simulação. Ambiente Construido (v. 10, n. 2), 27-40.

Clarke, J. A. A (2001). Energy Simulation in Building Design. Routledge. London (UK).

Costa, V. A. C. DA; Roriz, V. F.; Chvatal, K. M. S. (2017) Modeling of slab-on-grade heat transfer in EnergyPlus simulation program. Ambiente Construido (v. 17, $n$. 3), 117-135.

Didoné, E. L.; Pereira, F. O. R. (2010). Simulação computacional integrada para a consideração da luz natural na avaliação do desempenho energético de edificações. Ambiente Construído (v. 10, n. 4), 139154.

Didoné, E. L.; Wagner, A.; Pereira, F. O. R. (2014) Estratégias para edifícios de escritórios energia zero no Brasil com ênfase em BIPV. Ambiente Construído (v. 14, n. 3), 27-42.

Egan, J.; Finn, D.; Soares, P. H. D.; Baumann, V. A. R., Aghamolaei, R.; Beagon, P.; Neu, O.; Pallonetto, F. (2018) Definition of a useful minimal-set of accurately-specified input data for Building Energy Performance Simulation. Energy and Buildings (165), 172-183.

Freire, R. Z.; Oliveira, G. H. C.; Mendes, N. (2008) Development of regression equations for predicting energy and hygrothermal performance of buildings. Energy and Buildings, v. 40, n. 5, p. 810-820.

Gough, D.; Thomas, J.; Oliver, S (2012). Clarifying differences between review designs and methods. Systematic Reviews (1), 1-9.

Greici, R.; Ghisi, E. (2010). Avaliação do cálculo da iluminação natural realizada pelo programa EnergyPlus. Ambiente Construido, v. 10, n. 2, 157169.

Borgstein, E. H.; Lamberts, R. (2014). Developing energy consumption benchmarks for buildings: Bank branches in Brazil. Energy and Buildings, v. 82, 8291.

Hensen, J. L. M.; Lamberts, R. (2011). Introduction to Building Performance Modeling and Simulation. In: Hensen, J. L. M.; Lamberts, R. (edited by) (2011). Building Performance Simulation for Building and Operation. Routledge. London (UK).

Hernandez, A. Fundamentos da simulação energética de edificações. (2015). In: Edifício Ambiental. BODE, Joana Carlas Soares (edited by). Ed. Oficina de Textos. São Paulo (Brazil).

Mendes, N.; Lamberts, R.; Neto, J. A. B. C. (2001). Building simulation in brazil. Proceedings of Seventh International IBPSA Conference, p. 3-14. Rio de Janeiro (BRL), August 13-15, 2001.

Mendes, N.; Westphal, F. S.; Lamberts, R.; Neto, J. A. B. C. (2005). The use of computational tools for thermal and energy performance analysis of buildings in Brazil. Ambiente Construído (v. 5, n. 4), 47-68. 
Morandi, M. I. W. M.; Camargo, L. F. R. (2015). Revisão Sistemática de Literatura. In: A. Dresch; D. P. Lacerda; J. A. V. A. Júnior. Design Science Research - Método de Pesquisa para Avanço da Ciência e Tecnologia. Ed. Bookman. São Paulo (Brazil).

Neves, L. DE O.; Bernardini, S. P.; RUSCHEL, R. C.; Moreira, D. DE C. (2018). Revisões sistemáticas da literatura: parte I. PARC Pesquisa em Arquitetura e Construção (8), 141-143.

Pereira, C. D.; Ghisi, E. (2011). The influence of the envelope on the thermal performance of ventilated and occupied houses. Energy \& Buildings (v. 43, n. 12), 3391-3399.

Schmid, A. L. (2008). The introduction of building simulation into an architectural faculty: Preliminary findings. Journal of Building Performance Simulation (v. 1, n. 3), 197-208.

Silva, A. S.; Almeida, L. S. S.; Ghisi, E. (2016). Decisionmaking process for improving thermal and energy performance of residential buildings: A case study of constructive systems in Brazil. Energy and Buildings (128), p. 270-286.

Silva, A. S.; Ghisi, E. (2014). Uncertainty analysis of user behaviour and physical parameters in residential building performance simulation. Energy \& Buildings (76), 381-391.

Silva, A. S.; Ghisi, E. (2014) Análise comparativa dos resultados do desempenho térmico da envoltória de uma edificação residencial pelos métodos de simulação do RTQ-R e da NBR 15575-1. Ambiente Construido (v. 14, n. 1), 215-230.

Silva, A. S.; Ghisi, E. (2014). Uncertainty analysis of the computer model in building performance simulation. Energy and Buildings (76), p. 258-269.

Silva, A. S.; Ghisi, E. (2014). Uncertainty analysis of user behaviour and physical parameters in residential building performance simulation. Energy and Buildings (76), 381-391.

Silva, A. S.; Ghisi, E.; Lamberts, R. (2016). Performance evaluation of long-term thermal comfort indices in building simulation according to ASHRAE Standard 55. Building and Environment (102), 95-115.

Silva, A. S.; Sorgato, M. J.; Mazzaferro, L.; Melo, A. P.; Ghisi, E. (2014). Incerteza do método de simulação da NBR 15575-1 para a avaliação do desempenho térmico de habitações. Ambiente Construído (v. 14, $n$. 4), 103-117. 